\title{
Revitalisasi koridor komersial bersejarah Jalan Surabaya dengan konsep retrofitting di Kota Medan
}

\author{
Aulia Malik Affif \\ Universitas Sumatera Utara, Medan, Indonesia. amaffif@gmail.com \\ Dwi Lindarto Hadinugroho \\ Universitas Sumatera Utara, Medan, Indonesia. dwi.lindarto@usu.ac.id
}

\begin{abstract}
Abstrak
Jalan Surabaya telah terkenal sebagai kawasan distrik penjualan arloji sekaligus kawasan hunian pecinan yang pada masa Belanda disebut dengan nama Canton Straat. Seiring dengan perkembangan jaman kawasan ruas Jalan Surabaya mengalami degradasi kualitas visual dengan nilai historis yang melekat padanya. Penelitian bertujuan untuk menghasilkan konsep revitalisasi kawasan bersejarah Jalan Surabaya dengan pendekatan retrofitting. Dengan menggunakan metode deskriptif kualitatif, tahapan penelitian dimulai dengan melakukan analisis terhadap berbagai aspek dari kawasan, meliputi fisik, sosial, ekonomi dan budaya. Tiga strategi utama retrofitting digunakan untuk menghasilam model revitalisasi kawasan. Hasilnya penelitian menunjukkan bahwa revitalisasi kawasan Jalan Surabaya dapat ditempuh dengan cara pembangunan gerbang pecinan, ruang terbuka publik dan prasarana angkutan umum; signage, area parkir dan penataan pedestrian; serta konservasi bangunan bersejarah. Agar model revitalisasi dapat diterapkan maka membutuhkan dukungan semua pihak, termasuk partisipasi masyarakat setempat.
\end{abstract}

Kata kunci: revitalisasi kawasan, koridor komersial, retrofitting

\begin{abstract}
Jalan Surabaya has been known as a watch-selling district and a Chinatown residential area that, in the Dutch era, was called the Canton Straat. Along with the development of the era of Jalan Surabaya, the visual quality degrades with the historical value attached to it. This research aims to produce the concept of revitalizing the historic area of Jalan Surabaya with a retrofitting approach. A qualitative descriptive method used in the research with the stage begins by analyzing various aspects of the area, including physical, social, economic, and cultural aspects. Three main retrofitting strategies are used to produce a regional revitalization model. The results show that the Jalan Surabaya area's revitalization can be achieved by constructing a Chinatown gate, public open space, public transport infrastructure, signage, parking area, pedestrian arrangement, and historic buildings conservation. For the revitalization model to be implemented, it will require all parties' support, including local community participation.
\end{abstract}

Keywords: area revitalization, commercial corridors, retrofitting

Received: 2020-05-10 | Accepted: 2020-09-11 | DOI: 10.29080/eija.v6i1.914| Page: 65 - 77

EMARA: Indonesian Journal of Architecture

http://jurnalsaintek.uinsby.ac.id/index.php/EIJA

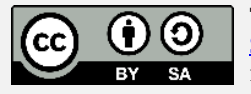

This article is open access distributed under the terms of the Creative Commons Attribution ShareAlike 4.0 International License, which permits unrestricted use, distribution, and reproduction in any medium provided the original work is properly cited. 


\section{Pendahuluan}

Pembangunan Kota Medan telah berkembang dengan signifikan, mulai dari pembanguan real estate sampai bangunan bertingkat tinggi hadir di tengah kota Medan. Namun, dengan pesatnya perkembangan tersebut, sejumlah bangunan bersejarah di kawasan bersejarah Kota Medan mulai kehilangan eksistensinya akibat dari maraknya pembangunan bangunan baru di kawasan niaga bersejarah (Liyushiana \& Sianipar, 2017).

Kawasan niaga bersejarah sering tidak mampu mempertahankan eksistensinya sebagai suatu penggerak roda ekonomi yang perkembangan keragaman jenis perniagaannya tidak sejalan dengan infrastruktur perkotaan. Hal ini memunculkan kemunduran perwajahan urban economics berupa penurunan vitalitas kawasan (Hadinugroho, 2017). Vitalitas merujuk kepada kondisi keefektifan suatu tempat dalam fungsinya sebagai utilitas pendukung kegiatan masyarakat kota (Lynch, 1984). Hal ini menyebabkan hilangnya ciri khas kawasan bersejarah dan lunturnya nilai sejarah pada kawasan tersebut.

Revitalisasi bertujuan untuk mengembalikan vitalitas ataupun daya hidup. Dalam konteks kawasan kota hal tersebut dapat diartikan sebagai upaya untuk mengembalikan vitalitas kawasan. Umumnya revitalisasi kawasan kota dikaitkan dengan proses peremajaan kawasan, dimana intervensi yang dilakukan dapat mencakup aspek fisik dan non-fisik, seperti ekonomi, sosial budaya, dan lain-lain (Martokusumo, 2008). Revitalisasi juga bertujuan untuk menciptakan kehidupan baru yang produktif serta mampu memberikan kontribusi positif pada kehidupan sosial budaya dan terutama kehidupan ekonomi (kawasan) kota (Martokusumo, 2006).

Salah satu model revitalisasi pada kawasan perkotaan adalah retrofitting. Retrofitting adalah pendekatan revitalisasi yang berbasis sustainable development. Retrofitting bertujuan untuk memanfaatkan kembali secara tepat suatu objek sebagai salah satu cara untuk mengembangkan objek atau tapak perancangan (Dunham-Jones \& Williamson, 2011). Terdapat tiga prinsip strategi retrofitting, yaitu: (1) $R e$ inhabitation, yaitu penggunaan ulang bangunan dengan konsep adaptive reuse pada bangunan yang ada untuk dapat menampung kegiatan masyarakat; (2) Redevelopment, yaitu pengembangan dan pembangunan berbagai macam bangunan dengan fungsi campuran, fasilitas transportasi yang bertujuan mengurangi ketergantungan kepada kendaraan bermotor dan kehidupan sosial yang lebih baik; (3) Regreening, yaitu penghijauan dalam bentuk ruang terbuka publik, taman dan dapat berupa berbagai perbaikan lingkungan (Dunham-Jones \& Williamson, 2011; Williamson, 2013).

Koridor Jalan Surabaya merupakan koridor komersial yang berada di dekat pusat Kota Medan telah dikenal sebagai kawasan distrik penjualan jam sekaligus kawasan pecinan. Jalan Surabaya dulunya bernama Canton Straat pada masa penjajahan Belanda (Buiskool, 2019). Jalan Surabaya sejak lama telah menjadi kawasan hunian sekaligus tempat berdagang mayoritas masyarakat etnis Tionghoa. Bangunan di koridor Jalan Surabaya kebanyakan berfungsi sebagai. Setiap bangunan tersebut memiliki gaya arsitektur peranakan shophouse's atau ecletic style yang umumnya dapat ditemukan di berbagai kota di Asia Tenggara. Peranakan shophouse's atau 
Ecletic Style merupakan sebuah gaya arsitektur yang mengadopsi elemen dan kesenian Tionghoa (Lutchman et al., 2014; Zwain \& Bahauddin, 2017) dan umumnya dapat ditemui di kawasan permukiman etnis Tionghoa di Asia Tenggara (Lutchman et al., 2014).

Namun seiring perkembangan zaman, bangunan dengan gaya arsitektur tersebut mulai kehilangan eksistensinya. Hal ini berdampak kepada mulai hilangnya ciri khas yang membedakan kawasan ruas Jalan Surabaya dengan kawasan lainnya. Degradasi kualitas visual tersebut sangat disayangkan karena kawasan pecinan dapat dikembangkan dan ditingkatkan kualitasnya menjadi kawasan yang dapat memberikan pengetahuan tentang budaya, arsitektur, sejarah dan kuliner. Fenomena menurunnya kualitas visual dan vitalitas kawasan ruas Jalan Surabaya beserta potensinya sebagai kawasan pecinan bersejarah menjadi dasar untuk melakukan upaya revitalisasi kawasan ruas Jalan Surabaya di Kota Medan dengan konsep retrofitting.

\section{Metode}

Penelitian ini menggunakan metode kualitatif deskriptif yang bertujuan untuk membuat deskripsi atas suatu fenomena sosial/alam secara sistematis, faktual dan akurat (Darjosanjoto, 2012). Data primer dikumpulkan melalui observasi lapangan dan wawancara, sedangkan data sekunder dikumpulkan melalui studi literatur. Lokasi penelitian berada di koridor Jalan Surabaya sepanjang \pm 450 meter yang berada di Kelurahan Pasar Baru, Kecamatan Medan Kota, Medan. Tahapan penelitian diawali dengan analisis berbagai aspek, seperti fisik, sosial, budaya dan ekonomi untuk mengetahui permasalahan yang ada pada kawasan. Analisis aspek fisik ditinjau melalui observasi terhadap 8 elemen fisik perancangan kota (Shirvani, 1985) yaitu tata guna lahan, bentuk dan massa bangunan, sirkulasi dan parkir, ruang terbuka hijau, area pedestrian, signage, aktivitas pendukung dan preservasi. Analisis aspek sosial, budaya dan ekonomi ditinjau dengan metode observasi dan wawancara kepada pemilik toko, pegawai toko dan petugas parkir. Dari hasil analisis, peneliti merumuskan model revitalisasi kawasan untuk merespon permasalahah aspek fisik, sosial, budaya dan ekonomi dengan berbasis tiga strategi utama retrofitting yaitu re-inhabitation, redevelopment dan regreening.

\section{Hasil dan Pembahasan \\ Aspek fisik koridor Jalan Surabaya}

Tata guna lahan

Jalan Surabaya telah di tetapkan menjadi kawasan perdagangan atau niaga sejak tahun 1915 (gambar 1). Hasil observasi kawasan juga menunjukkan bahwa mayoritas bangunan pada koridor Jalan Surabaya memiliki fungsi perdagangan atau niaga yang difungsikan juga sebagai hunian, kemudian diikuti oleh perkantoran dan juga hotel (gambar 2). Tata guna lahan (land use) merupakan salah satu elemen kunci dalam perancangan kota untuk menentukan perancangan dua dimensional, yang kemudian akan menentukan ruang tiga dimensional. Kebijaksanaan tata guna lahan membentuk hubungan antara sirkulasi, parkir dan kepadatan aktivitas pengguna individual (Shirvani, 1985).

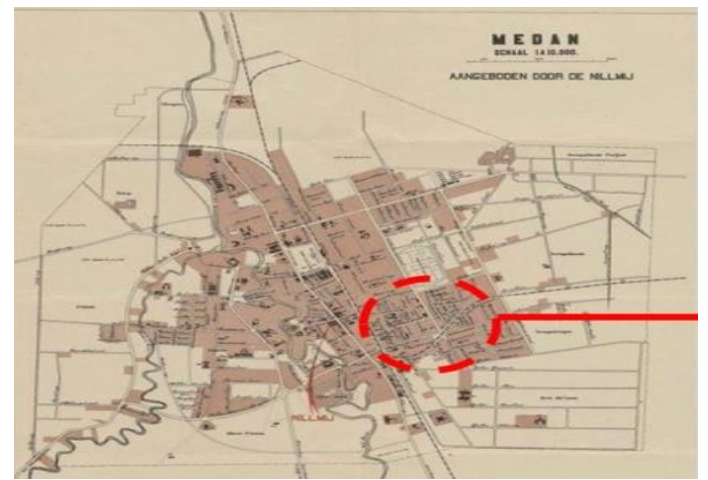

Gambar 1. Peta Kota Medan Tahun 1915 (sumber: Sofyan, 2019) 


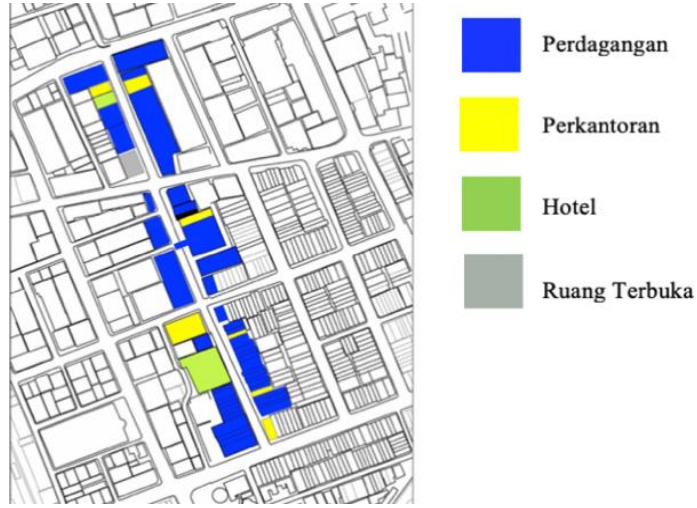

Gambar 2. Tata guna lahan koridor Jalan Surabaya (sumber: hasil analisis, 2019)

\section{Bentuk dan massa bangunan}

Hasil pengamatan lapangan menunjukkan bahwa hanya sebagian kecil bangunan yang masih mempertahankan fasad bergaya Peranakan shophouse's atau Ecletic Style. Sedangkan sebagian besar bangunan lain telah di desain ulang dengan langgam atau style yang berbeda dengan bangunan aslinya (gambar 3).
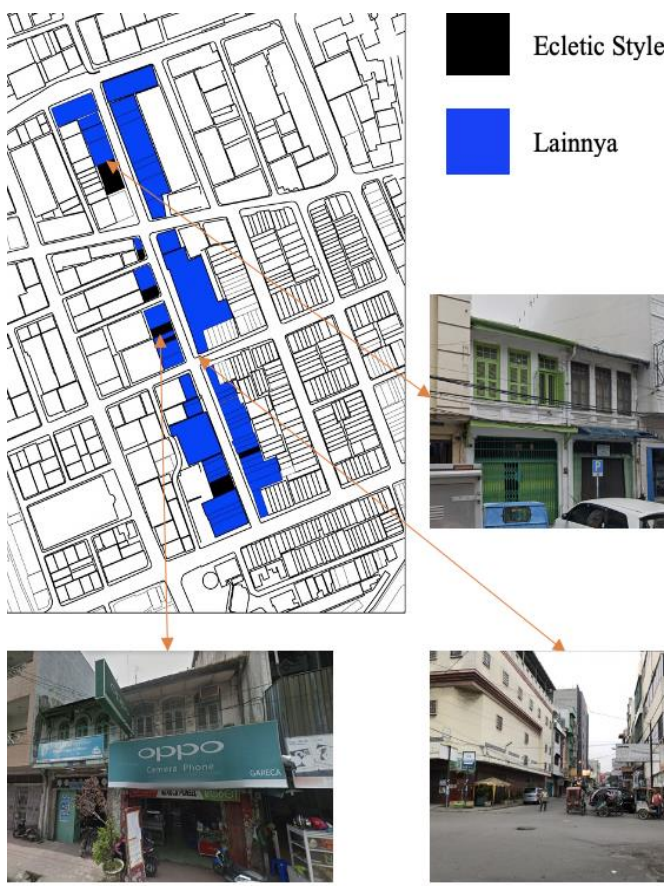

Gambar 3. Sebaran bangunan berdasarkan gaya fasad bangunan di sepanjang koridor Jalan Surabaya (sumber: hasil analisis, 2019)

Sedangkan berdasarkan ketinggian lantai bangunan, kawasan koridor Jalan Surabaya didominasi oleh bangunan dengan ketinggian lantai mencapai 3-4 lantai (gambar 4). Masih ditemukan bangunan berlantai dua yang merupakan bangunan bersejarah era kolonial Belanda. Selain itu terdapat bangunan hotel dengan ketinggian mencapai 7 lantai. Pada penataan suatu kota, bentuk dan hubungan antara massa seperti ketinggian bangunan, pengaturan massa bangunan dan lain-lain harus diperhatikan sehingga ruang yang terbentuk teratur, mempunyai garis langit yang dinamis serta menghindari adanya lost space atau ruang tidak terpakai (Shirvani, 1985).

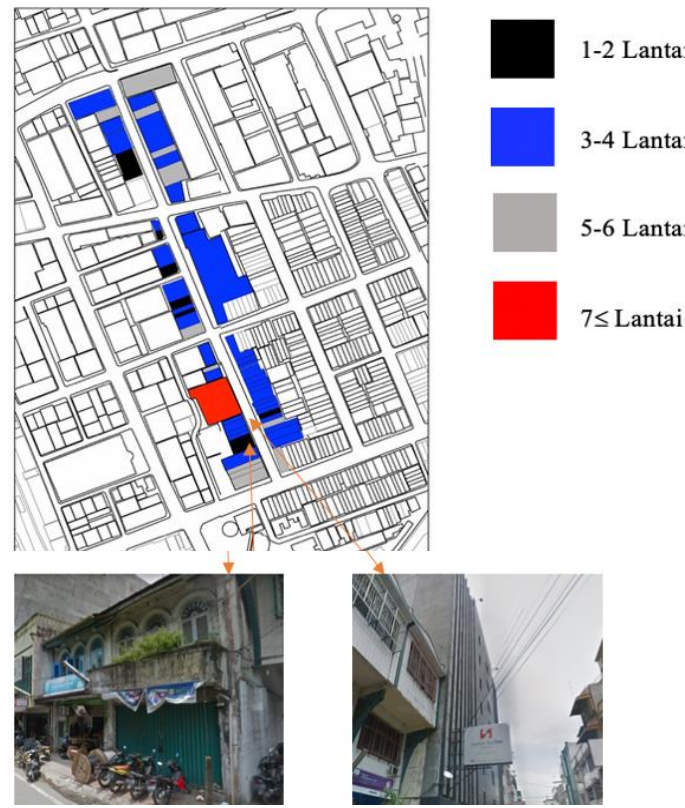

Gambar 4. Sebaran bangunan berdasarkan ketinggian lantai di sepanjang koridor Jalan Surabaya (sumber: hasil analisis, 2019)

\section{Sirkulasi dan parkir}

Sirkulasi kendaraan pada kawasan koridor jalan Surabaya adalah satu arah, dengan arus lalu lintas relatif lancar dan lokasi parkir kendaraan hanya berada di sisi kiri jalan (gambar 5). Dengan perbedaan lokasi parkir, maka terlihat pula perbedaan aktivitas pedagang dan pejalan kaki yang cenderung berlalulalang di sisi kiri koridor, sehingga sisi kanan koridor cenderung lebih lengang. Shirvani (1985) menyatakan bahwa terdapat tiga prinsip utama dalam menangani sirkulasi, yaitu jalan harus menjadi elemen ruang terbuka yang meningkatkan kualitas visual; jalan harus memberi orientasi terhadap pengemudi serta menciptakan lingkungan 
yang mudah dipahami; dan sektor publik dan swasta harus bekerja sama demi mewujudkan tujuan tersebut. Elemen parkir pada kawasan perkotaan juga telah memiliki dua dampak langsung terhadap lingkungannya, yaitu menghidupkan aktivitas komersial serta menimbulkan dampak visual yang buruk terhadap bentuk fisik dan struktur perkotaan (Shirvani, 1985).
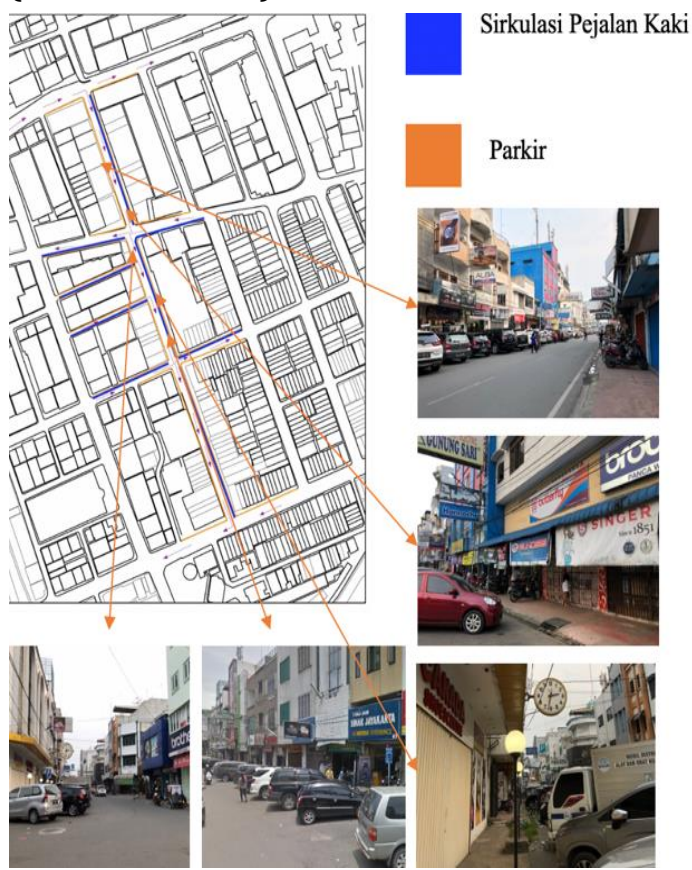

Gambar 5. Pola dan situasi sirkulasi serta parkir di sepanjang koridor Jalan Surabaya (sumber: hasil analisis, 2019)

\section{Ruang terbuka}

Di persimpangan Jalan Surabaya dan Jalan Bandung terdapat lahan kosong yang dapat di manfaatkan menjadi ruang terbuka hijau untuk peningkatan vitalitas kawasan Jalan Surabaya (gambar 6). Pada kawasan ini telah terdapat elemen ruang terbuka seperti vegetasi. Ruang terbuka adalah semua kenampakkan lansekap, hardscape (jalan, trotoar dan sebagainya), taman dan ruang rekreasi di kota. Berbagai elemen ruang terbuka meliputi lapangan hijau, ruang hijau kota, pepohonan, pagar, tanamanan, air, penerangan, paving, kios, tempat sampah, air minum, sculpture, jam, dan lain-lain (Shirvani, 1985).

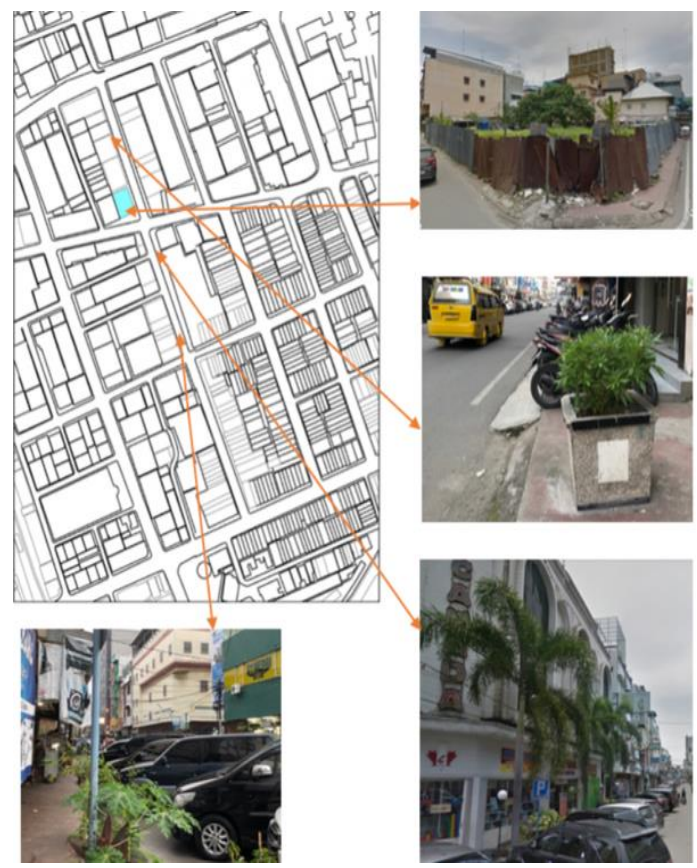

Gambar 6. Situasi ruang terbuka di sepanjang koridor Jalan Surabaya (sumber: hasil analisis, 2019)

\section{Area pedestrian}

Area pedestrian di sepanjang koridor Jalan Surabaya telah tersedia dan terkoneksi antara satu sama lainnya. Area pedestrian Jalan Surabaya memiliki dimensi 1,2 - 1,8 meter. Belum tersedianya parkir khusus sepeda motor pada kawasan ini menyebabkan sepeda motor diparkir di atas area pedestrian. Selain itu para pemilik bangunan banyak yang membangun ramp atau tangga di atas area pedestrian sebagai sarana akses menuju ke bangunannya (gambar 7).

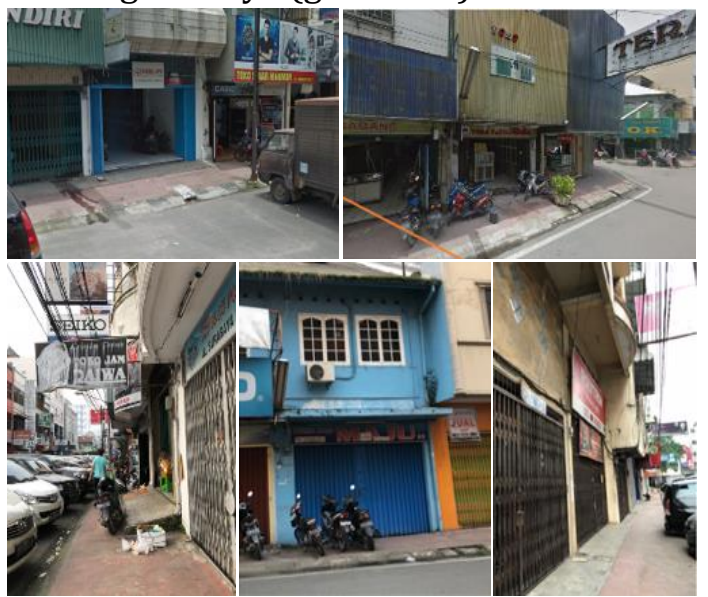

Gambar 7. Situasi area pedestrian di sepanjang koridor Jalan Surabaya (sumber: hasil analisis, 2019) 
Fasilitas pedestrian seperti tong sampah, area duduk dan lampu masih minim ditemukan. Padahal desain area pedestrian yang baik dapat menurunkan ketergantungan individu terhadap kendaraan bermotor, meningkatkan kualitas udara dan meningkatkan aktivitas perdagangan (Shirvani, 1985).

\section{Signage}

Berdasarkan hasil pengamatan, kondisi reklame yang menggantung dari toko-toko yang menjorok ke badan jalan masih belum tertata dengan baik. Penempatan lokasi reklame antara satu dengan yang lainnya belum selaras sehingga menimbulkan kesan kurang harmonis (gambar 8). Menurut PERMEN PU No.20/PRT/M/2010 Pasal 10, penentuan lokasi merupakan faktor yang sangat mempengaruhi penataan tata informasi agar terlihat rapi dan teratur, serta tidak mengganggu keamanan dan keselamatan pengguna jalan. Sedangkan penanda parkir, informasi biaya parkir dan marka jalan telah berada di lokasi yang baik dan dapat dengan mudah ditemukan.

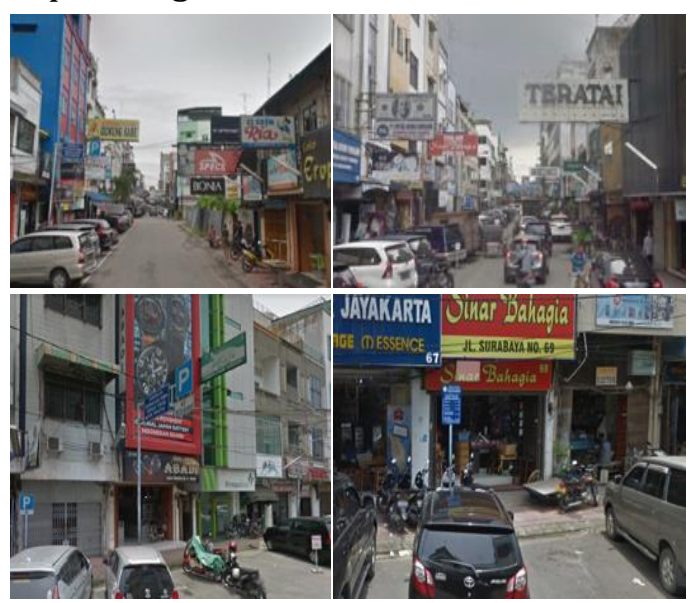

Gambar 8. Situasi signage di sepanjang koridor Jalan Surabaya (sumber: hasil analisis, 2019)

Maka untuk mengangkat nilai estetika suatu tempat dibutuhkan desain tata informasi berkarakter yang dapat merefleksikan karakter tempat itu sendiri. Agar penerapannya tidak menimbulkan kepadatan, dan ketidakteraturan visual, perlu adanya penataan jarak pemasangan antar signage. Selain itu penggunaan signage harus dapat merefleksikan karakter kawasan, dalam hal ini kawasan pendidikan, serta harmonis dengan bangunan tempat signage tersebut berada (Shirvani, 1985).

\section{Aktivitas pendukung}

Aktivitas pendukung merupakan semua fungsi bangunan dan setiap kegiatan yang mendukung ruang publik suatu kawasan kota (Shirvani, 1985). Segala bentuk dukungan terhadapa aktivitas dapat berwujud elemen fisik kota seperti tata ruang luar, street furniture dan peruntukan lahan yang menunjang hubungan pada kegiatan utama kota/kawasan (Adwitya, 2017). Aktivitas pendukung pada kawasan ini kebanyakan berupa pedagang kaki lima. Karena sifatnya yang tidak permanen, peletakannya masih belum teratur dan tertata dengan baik. Terdapat pangkalan becak motor yang keberadaannya dapat mendukung keberlangsungan aktivitas yang ada pada lokasi penelitian.

\section{Preservasi}

Kawasan Jalan Surabaya atau yang dulunya bernama Canton Straat telah menjadi kawasan permukiman khusus etnis Tionghoa dan juga sejak tahun 1915 telah di tetapkan oleh pemerintahan kolonial Belanda sebagai kawasan komersial (gambar 9).

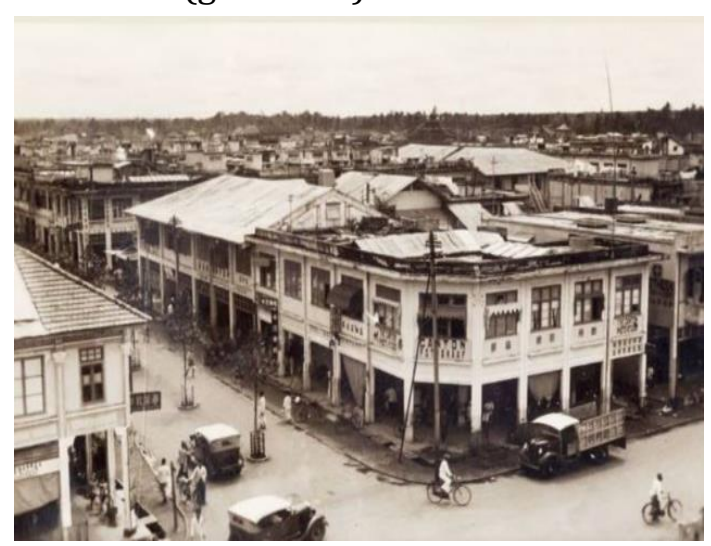

Gambar 9. Situasi Persimpangan Canton Straat dan Hakka Straat di tahun 1930 (sumber: Hoepoedio, 2019) 
Identifikasi aspek preservasi dilakukan kepada 16 bangunan yang masih mempertahankan bentuk fasad aslinya dan yang melakukan perubahan minor terhadap fasadnya. Setiap bangunan tersebut bercorak Eclectic Style atau Peranakan shophouse's. Bangunan yang tersisa ini harus dipertahankan dan dipelihara kondisinya serta direhabilitasi agar kondisi fisik bangunan menjadi lebih prima. Bangunan-bangunan tersebut adalah aset bersejarah yang tersisa dari kawasan ini sehingga nilai sejarah dan estetikanya harus tetap terjaga. Preservasi memberi manfaat pada lingkungan masyarakat, yaitu manfaat dari segi kebudayaan, ekonomi, sosial dan perencanaan (Shirvani, 1985).

\section{Aspek sosial koridor Jalan Surabaya}

Hubungan sosial yang tercipta di kawasan ini terlihat pada interaksi dua arah antara konsumen dengan pedagang. Setting interaksi sosial tersebut hanya terjadi pada toko atau bangunannya masingmasing. Tidak terdapat sebuah tempat yang dapat mewadahi kegiatan dan interaksi sosial antar masyarakat dalam skala yang lebih luas.

Dari hasil wawancara dengan narasumber yang berprofesi sebagai pemilik toko, mengungkapkan bahwa narasumber telah mengenal hampir 80 persen masyarakat yang tinggal di kawasan Jalan Surabaya. Interaksi sosial pun berjalan dengan baik, walau interaksi umumnya terjadi saat berada di rumah ibadahnya yang berada dilingkungan sekitarnya (Vihara dan Gereja). Jika berdasarkan klasifikasi usia, sarana rekreasi masyarakat setempat terbagi menjadi dua bagian yakni pusat perbelanjaan untuk kelompok usia anakanak hingga dewasa, serta Warung kopi atau sarana publik, seperti Taman Ahmad Yani atau Lapangan Merdeka bagi kelompok lanjut usia (lansia).

\section{Aspek budaya koridor Jalan Surabaya}

Selain terkenal sebagai sentra penjualan jam, terdapat juga kuliner legendaris Kota Medan "Es Krim Ria" yang telah berdiri sejak tahun 1936 di Jalan Surabaya. Walaupun dikenal seabgai kawasan pecinan, tetapi kawasan Jalan Surabaya tidak terlalu mencerminkan ragam kebudayaan khas Tionghoa, mulai dari bentuk fisik mupun non fisik, seperti arsitektur, ornamen, kuliner dan hingga kesenian khas Tionghoa. Tidak juga ditemui toko yang menjual berbagai produk khas Tionghoa (kerajinan, obat tradisional dan lain-lain). Dari penuturan beberapa narasumber, kegiatan yang berkaitan dengan kebudayaan Tionghoa di kawasan Jalan Surabaya hanya pada saat perayaan hari-hari besar seperti Cap Go Meh atau Imlek saja. Keberadaan toko yang menjual kebutuhan dan kerajian khas Tionghoa serta warung kopi tradisional (kopitiam) masih cukup marak pada era sebelum tahun 1990-an. Tetapi pasca tahun 1990-an keberadaan toko jam mulai menjamur dan mendominasi hingga saat ini.

\section{Aspek ekonomi koridor Jalan Surabaya}

Aktivitas perniagaan pada kawasan Jalan Surabaya cenderung kalah ramai jika dibandingkan dengan koridor komersial lainnya yang berada dis sekitar Jalan Surabaya, seperti Jalan Semarang, Jalan Cirebon dan Jalan Bandung. Keberlangsungan aktivitas niaga Jalan Surabaya lebih banyak terjadi pada 200250 meter pertama kawasan. Berdasarkan informasi dari para responden, bila dibandingkan kegiatan perniagaan di era tahun 1960-1990an maka kondisi saat ini telah menurun drastis, yang berimbas pada menurunnya omzet penjualan pedagang di kawasan Jalan Surabaya. Maraknya keberadaan pusat perbelanjaan modern (mall) dan toko online memicu perubahan pola transaksi yang membuat 
kawasan Jalan Surabaya tidak seramai sebelumnya (Harian Medan Bisnis, 2013).

\section{Model revitalisasi koridor Jalan Surabaya}

Dari hasil analisis terhadap berbagai aspek koridor Jalan Surabaya maka disusunlah konsep revitalisasi koridor komersial bersejarah Jalan Surabaya berbasis retrofitting.

\section{Pembangunan Gerbang Pecinan}

Bentuk fisik lingkungan khas Tionghoa di kawasan Jalan Surabaya masih belum terlihat. Untuk menguatkan karakter fisik yang mencerminkan kebudayaan Tionghoa maka diajukan perancangan gerbang pecinan sebagai identitas fisik lingkungan (gambar 10).
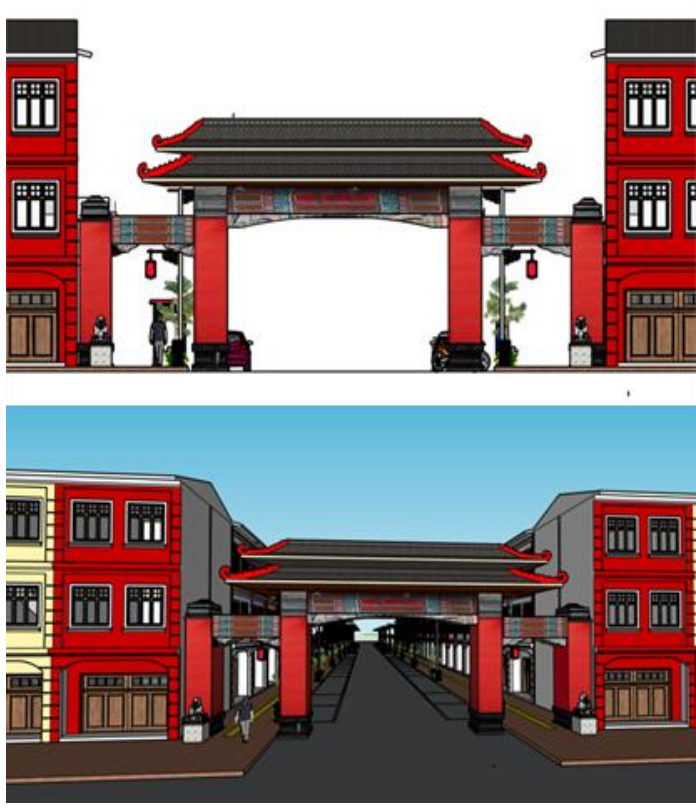

Gambar 10. Ilustrasi model gerbang pecinan di koridor Jalan Surabaya (sumber: hasil analisis, 2019)

Gerbang pecinan menjadi hal yang lazim ditemukan di kawasan pecinan dimanapun di dunia ini, sebagai salah satu orientasi kawasan Pecinan. Lokasi gerbang pecinan Jalan Surabaya akan berada di dua titik persimpangan yakni persimpangan Jalan Surabaya dan Jalan MT Haryono sebagai titik masuk kawasan Jalan Surabaya, serta di persimpangan Jalan Surabaya dan Jalan Pandu sebagai titik keluar kawasan Jalan Surabaya. Gerbang pecinan juga dapat menjadi orientasi masyarakat yang hendak menuju kawasan pecinan Jalan Surabaya dan diharapkan, kehadiran gerbang pecinan dapat meningkatkan vitalitas kawasan Jalan Surabaya.

\section{Penataan signage}

Kondisi papan reklame pada Jalan Surabaya yang masih belum tertata dengan baik dan selaras menyebabkan kesan semrawut dan kurang harmonis. Penataan signage telah diatur dalam Peraturan Walikota Medan Nomor 17 tahun 2019. Namun belum terdapat tindak lanjut dari pemerintah daerah terkait pedoman teknis perencanaan dan perancangan reklame yang lebih jelas. Dengan hadirnya pedoman teknis tersebut, penataan reklame akan lebih dapat diimplementasikan. Keselarasan dan keterorganisiran dapat diciptakan antar satu reklame dengan reklame lainnya. Harmonisasi signage akan menjadi daya tarik tersendiri dari kawasan Jalan Surabaya itu sendiri.

Beberapa metode penataan reklame dirumuskan untuk kawasan Jalan Surabaya (gambar 11), antara lain: (1) reklame merk usaha pada dinding bangunan sebaiknya ditempatkan pada bagian atas lantai satu bangunan dengan luas $\pm 15 \%$ luas dinding depan bangunan; (2) reklame merk usaha yang menggantung pada bangunan, panjangnya tidak boleh lebih dari 1 meter dari bangunan dan tidak boleh memiliki tinggi lebih dari bangunannya sehingga tidak menutupi fasad bangunan; (3) desain reklame merk usaha harus kompatibel dengan arsitektur bangunan dan reklame di sekitarnya; (4) penempatan reklame iklan/sponsor hanya pada reklame berdiri atau standing signage dengan dimensi $70 \mathrm{x}$ $130 \mathrm{~cm}$ yang tersedia setiap 25 meter (lihat gambar 12); dan (5) papan reklame merk usaha dan reklame iklan/sponsor merupakan neon box yang memiliki 
pencahayaan tambahan berupa lampu sorot sehingga dapat menambah pencahayaan pada malam hari

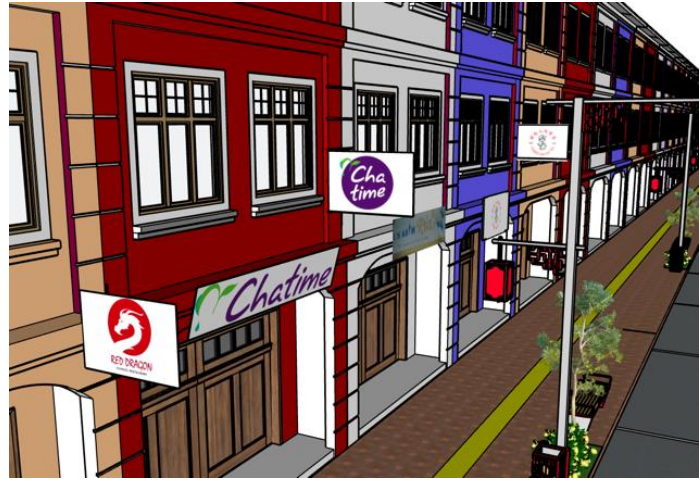

Gambar 11. Ilustrasi penataan signange di kawasan koridor Jalan Surabaya (sumber: hasil analisis, 2019)

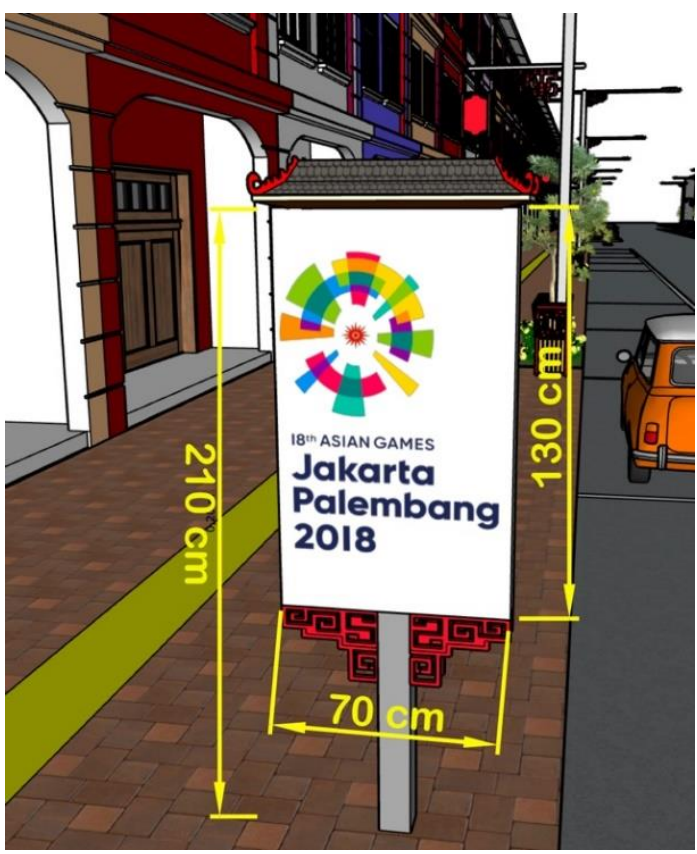

Gambar 12. Ilustrasi ketentuan reklame berdiri iklan/sponsor di kawasan koridor Jalan Surabaya (sumber: hasil analisis, 2019)

\section{Konservasi bangunan bersejarah}

Bangunan di sepanjang koridor Jalan Surabaya yang masih mempertahankan gaya aslinya atau telah melakukan perubahan minor terhadap fasadnya harus tetap dipertahankan dan dikonservasi untuk memberikan penyegaran terhadap wujud fisik bangunan tanpa merubah langgam arsitekturnya. Terhadap bangunan bergaya arsitektur Eclectic Style atau Peranakan shophouse's yang tidak produktif lagi, dalam artian aktivitas niaganya rendah, dapat menerapkan konsep adaptive reuse yang sesuai dengan salah satu prinsip retrofitting yaitu reinhabitation. Dengan prinsip reinhabitation maka bangunan dapat digunakan ulang namun dengan fungsi yang berbeda. Untuk menghadirkan fungsi baru, dapat melibatkan masyarakat pada sebuah kawasan, yang outputnya akan meningkatkan aktivitas ekonomi pada kawasan tersebut (Dunham-Jones \& Williamson, 2011). Salah satu fungsi baru yang dapat diajukan adalah fungsi museum atau heritage center maupun pusat pelatihan kerajinan khas Tionghoa.

\section{Penataan area parkir}

Tidak tersedianya area parkir untuk sepeda motor menyebab area pedestrian beralih fungsi sebagai area parkir motor. Selain itu parkir mobil yang hanya tersedia disisi kiri jalan dengan konfigurasi miring 60 derajat, cukup memakan badan jalan dan menyebabkan aktivitas pada koridor disisi kanan jalan lebih rendah dibanding koridor disisi kiri jalan. Untuk menyikapi kondisi tersebut maka model penataan area parkir diubah menjadi parkir paralel di kedua sisi jalan. Selain itu juga ditambahkan garis pembatas parkir, area khusus parkir motor dan mesin pembayaran parkir elektronik (gambar 13).

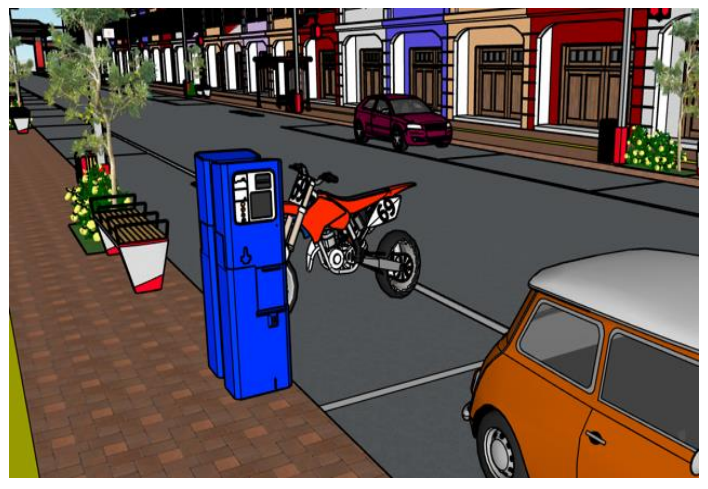

Gambar 12. Ilustrasi setting penataan area parkir di koridor Jalan Surabaya (sumber: hasil analisis, 2019)

Melalui setting tersebut diharapkan arus sirkulasi kendaraan bermotor semakin lancar dan kedua sisi koridor 
komersial memiliki tingkat aktivitas yang sama.

\section{Pembangunan prasarana angkutan umum}

Sesuai dengan prinsip retrofitting, yaitu redevelopment, yang menekankan kepada upaya pengembangan kawasan dengan mengurangi ketergantungan terhadap kendaraan bermotor pribadi, maka keberadaan prasarana angkutan umum seperti halte menjadi penting. Dengan hadirnya halte yang dirancang dengan mengikuti konteks identitas kawasan (gambar 13) serta ditunjang dengan ketersediaan angkutan umum yang aman dan nyaman, maka penggunaan kendaraan bermotor pribadi di kawasan Jalan Surabaya secara bertahap dapat berkurang berkurang.

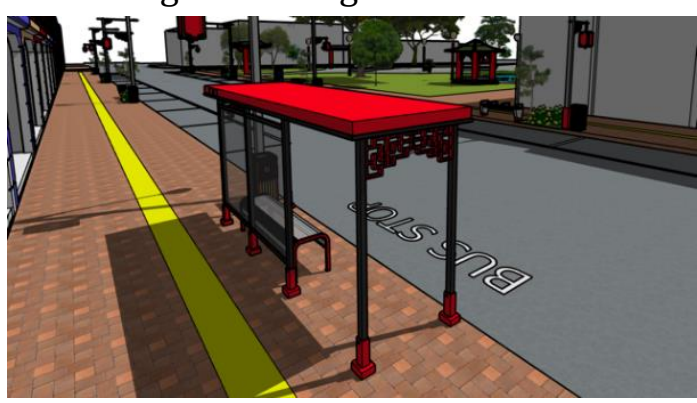

Gambar 13. Ilustrasi disain halte di sepanjang koridor Jalan Surabaya (sumber: hasil analisis, 2019)

\section{Penataan area pedestrian}

Penataan area pedestrian berangkat dari kondisi eksisting area pedestrian yang belum nyaman untuk dilalui serta belum tersedianya elemen street furniture yang memadai. Konsep perancangan area pedestrian dimulai dengan memperlebar dimensi pedestrian yang semula 1,2-1,8 meter menjadi 4 meter. Penambahan dimensi area pedestrian agar arus sirkulasi pejalan kaki tidak terganggu oleh street furniture dan memberi rasa nyaman terhadap para pejalan kaki. Sejalan dengan pembangunan prasarana angkutan umum, penataan area pedestrian pun harus dilakukan sebagai salah satu prinsip retrofitting yaitu redevelopment yang bertujuan membangunan dan mengembangkan kawasan dengan mengurangi ketergantungan terhadap kendaraan bermotor pribadi. Jaringan area pedestrian yang luas, area pedestrian yang aman dan nyaman serta terhubung dengan mode transportasi massal akan menjadikan kawasan tersebut walkable (Southworth, 2005). Berbagai fasilitas penunjang seperti vegetasi, tong sampah, bangku dan lampu jalan disediakan disepanjang jalur pedestrian (gambar 14).

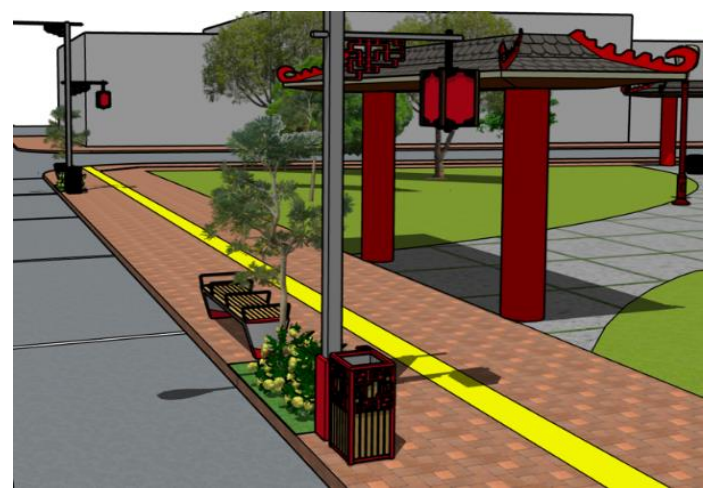

Gambar 14. Ilustrasi elemen street furniture di area pedestrian koridor Jalan Surabaya (sumber: hasil analisis, 2019)

Tong sampah, bangku dan lampu jalan dirancang dengan mengadopsi dari bentukan ornamen khas Tionghoa agar dapat menguatkan identitas kawasan. Secara umum area pedestrian akan dibagi menjadi tiga zonasi yaitu: (1) window shopping lane; (2) pedestrian through lane; dan (3) furnishing zone (gambar 15).

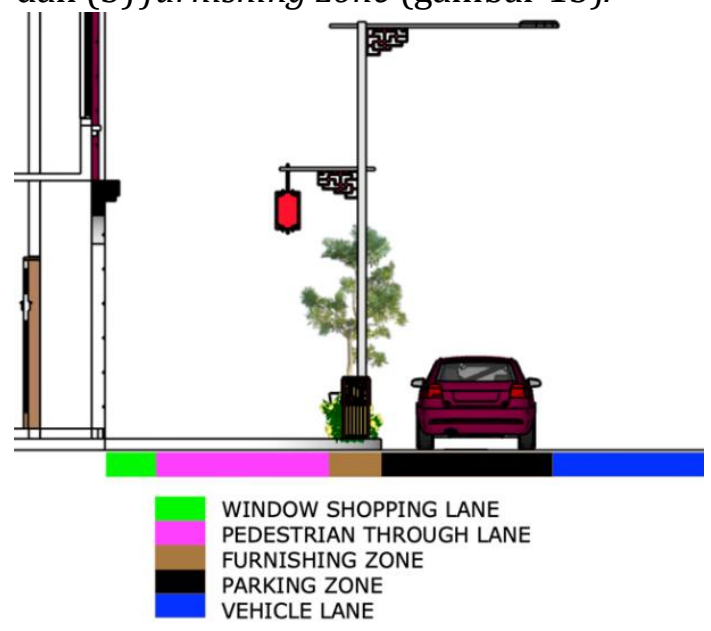

Gambar 15. Ilustrasi konsep zonasi di area pedestrian koridor Jalan Surabaya (sumber: hasil analisis, 2019) 


\section{Pembangunan ruang terbuka publik}

Kondisi eksisting ruang terbuka yang ada pada persimpangan Jalan Surabaya dan Jalan Bandung adalah sebuah tanah kosong. Lahan ini berpotensi dimanfaatkan sebagai ruang terbuka publik karena letaknya yang berada di pertemuan dua ruas jalan serta berada dekat i Es Krim Ria yang merupakan tempat kuliner bersejarah pada kawasan koridor Jalan Surabaya. Salah satu konsep retrofitting, yaitu regreening akan diterapkan, salah satunya melalui pembangunan ruang terbuka publik. Hadirnya ruang terbuka publik akan dapat menampung berbagai aktivitas pada kawasan Jalan Surabaya mulai dari kegiatan kebudayaan (Imlek atau Cap Go Meh), kegiatan sosial yang bersifat rekreasional (gazebo, skatepark, dll) hingga kegiatan ekonomi seperti penyelenggaraan bazar. Ruang terbuka publik diharapkan dapat mengakomodir aktivitas masyarakat dari berbagai macam kategori umur (gambar 16).

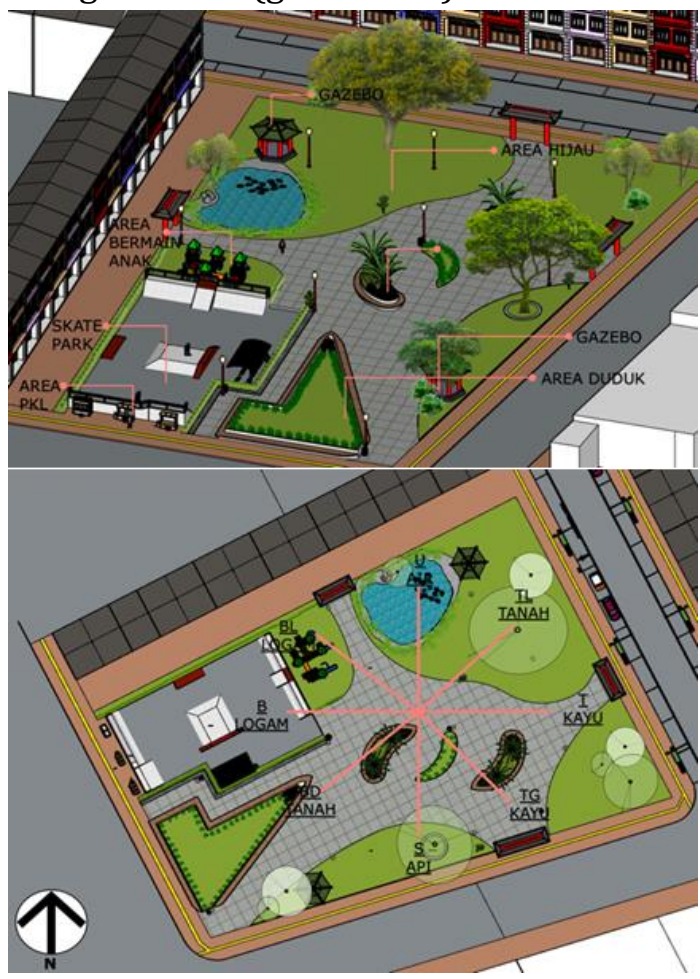

Gambar 16. Ilustrasi konsep ruang terbuka publik di kawasan koridor Jalan Surabaya (sumber: hasil analisis, 2019)
Feng Shui merupakan ilmu dan kepercayaan dari daratan tiongkok kuno yang bertujuan untuk menata bangunan dan lingkungan sesuai dengan keselarasan dan merupakan kompas kehidupan yang mengatur keseimbangan elemen alam seperti angin, air, tanah dan logam (Loho et al., 2017). Penataan letak elemenelemen pada ruang terbuka publik Jalan Surabaya akan didasarkan kepada konsep arah dan elemen Feng Shui.

\section{Kesimpulan}

Model revitalisasi koridor komersial bersejarah Jalan Surabaya menitikberatkan kepada tujuh aspek utama revitalisasi, yaitu: pembangunan gerbang pecinan, penataan signage, konservasi bangunan bersejarah, penataan area parkir, pembangunan prasarana angkutan umum. penataan area pedestrian, serta pembangunan ruang terbuka publik. Dengan menerapkan tujuh aspek ini diharapkan koridor komersial Jalan Surabaya dapat menjadi sentra kegiatan budaya dan sejarah etnis Tionghoa di Kota Medan. Model revitalisasi ini membutuhkan dukungan dan partisipasi setiap piha yang terlibat, terutama masyarakat etnis Tionghoa di kawasan Jalan Surabaya. Dengan demikian kelestarian koridor Jalan Surabaya sebagai kawasan pecinan bersejarah akan tetap terjaga.

\section{Pernyataan Penulis}

Dengan ini penulis menyatakan bahwa penelitian ini terbebas dari konflik kepentingan dengan pihak manapun

\section{Ucapan Terimakasih}

Penulis mengucapkan terimakasih kepada Universitas Sumatera Utara Medan serta semua pihak yang telah mendukung kegiatan penelitian ini.

\section{Referensi}

Adwitya, F. X. H. (2017). Kajian Pengaruh Perkembangan Activity Support (kegiatan Pendukung) Fasilitas 
Pendidikan Terhadap Elemen Perancangan Kawasan Pada Koridor Jalan Seturan Raya [Thesis, Universitas Atma Jaya Yogyakarta]. http://e-journal.uajy.ac.id/11915/

Buiskool, D. A. (2019). Prominent Chinese During the Rise of a Colonial City: Medan 1890-1942 [Doctoral Disertation, Utrecht University]. https://www.narcis.nl/publication/ RecordID/oai:dspace.library.uu.nl:1 $874 \% 2 F 386003$

Darjosanjoto, E. T. S. (2012). Penelitian arsitektur di bidang perumahan dan permukiman (1st ed.). ITS Press. https://opac.perpusnas.go.id/Detail Opac. aspx?id=999456

Dunham-Jones, E., \& Williamson, J. (2011). Retrofitting Suburbia, Updated Edition: Urban Design Solutions for Redesigning Suburbs. John Wiley \& Sons.

Hadinugroho, D. L. (2017). Kajian Model Revitalisasi Kawasan Heritage Kesawan Medan. Prosiding Temu Ilmiah IPLBI 2017, 45-52. https://doi.org/10.32315/sem.1.b0 45

Harian Medan Bisnis. (2013). Jalan Surabaya, Pusat Bisnis yang Tersisih akibat Persaingan. Medan Bisnis Daily.

https://www.medanbisnisdaily.co m:443/news/read/2013/11/14/61 741/jalan_surabaya_pusat_bisnis_y ang_tersisih_akibat_persaingan/

Hoepoedio, B. (2019). Dan Hakkastraat, Medan, $1930 . \quad$ Pinterest. https://id.pinterest.com/pin/4755 52041905565729/

Liyushiana, \& Sianipar, C. (2017). Pengelolaan Koridor Jalan Ahmad Yani Sebagai Daya Tarik Wisata Pusaka. Khasanah Ilmu - Jurnal Pariwisata Dan Budaya, 8(2), 45-59. https://doi.org/10.31294/khi.v8i2. 2409

Loho, J. B., Siregar, F. O. P., \& Egam, P. P. (2017). Memorial Park Di Manado "Feng Shui Dalam Gubahan Bentuk dan Ruang Arsitektur". Jurnal Arsitektur DASENG, 6(1), 64-73. https://ejournal.unsrat.ac.id/index. php/daseng/article/view/14790

Lutchman, C., Evans, D., Hashemi, W. S. G. A., \& Maharaj, R. (Eds.). (2014). 'Sino-Portuguese': The significance of the Shophouse definition in Southern peninsula, Thailand. In 7 Fundamentals of an Operationally Excellent Management System (pp. 83-98). CRC Press.

Lynch, K. (1984). Good City Form. MIT Press.

Martokusumo, W. (2006). Revitalisasi dan Rancang Kota: Beberapa Catatan dan Konsep Penataan Kawasan Kota Berkelanjutan. Journal of Regional and City Planning, 17(3), 31-46. http://journals.itb.ac.id/index.php/ jpwk/article/view/4244

Martokusumo, W. (2008). Revitalisasi, Sebuah Pendekatan Dalam Peremajaan Kawasan. Journal of Regional and City Planning, 19(3), 57-73.

http://journals.itb.ac.id/index.php/ jpwk/article/view/4205

Shirvani, H. (1985). The urban design process. Van Nostrand Reinhold.

Sofyan, A. (2019). Medan aangeboden door de Nillmij_ca 1915 (Indonesian History: Medan, North Sumatra) [Digital map]. Pinterest. https://id.pinterest.com/pin/3983 57529512817275/

Southworth, M. (2005). Designing the Walkable City. Journal of Urban Planning and Development, 131(4), 246-257. https://doi.org/10.1061/(ASCE)07 33-9488(2005)131:4(246)

Williamson, J. (2013). Designing Suburban Futures: New Models from Build a Better Burb. Island Press.

Zwain, A., \& Bahauddin, A. (2017). The Sustainable Architectural Values of Eclectic Style Shophouses Case Study: Sun Yat Sen Museum Penang, Malaysia. Panggung, 27(2), 1-9. https://doi.org/10.26742/panggun g.v27i2.253 


\section{Kontribusi Penulis}

Aulia Malik Affif berkontribusi dalam penyusunan konsep penelitian, metodologi, investigasi, analisis data, visualisasi serta penyusunan draft artikel dan revisi.

Dwi Lindarto Hadinugroho berkontribusi dalam metodologi. supervisi dan validasi 